\title{
(SELF-MANAGED) URBAN RESILIENCE AND MASS SOCIAL HOUSING
}

\author{
Evandro Holz*
}

\begin{abstract}
The outlook on urban resilience has gone through significant evolution. Its concept has been broadened from an emphasis on endurance of functions, through a focus on adaptability of systems, towards transformative capabilities in the face of uncertainty of events. Most notably, new visions acknowledge both short-term 'shocks' (e.g. hurricanes) and longer-term 'stresses' (e.g. inequality), recognising crises as intrinsic to the complexities of the world we live in, and actually necessary for our progress. To encompass the uneven and unpredictable circumstances that are experienced, it is essential that we acknowledge the empowerment of citizens, along with the tangible and intangible assets (e.g. infrastructure and education, respectively), as the main drivers of change (which are refered to as 'self-managed resilience').
\end{abstract}

Social housing programmes present a great opportunity to build on this new perspective on resilience. They allow the transformation of a set of issues (including shocks, e.g. natural disaster, and stresses, e.g. poverty) into an opportunity to embrace change and evolve from it. However, they often cause a big disruption in the city fabric and, in the longterm, even replicate the problems beneficiaries faced before it. This paper shows how the application of new urban resilience perspectives in social housing, particularly via self-managed practices, can minimise the occurrence of these issues. Drawing on experiences in Brazil, it describes the positive effects in social, economic and environmental resilience derived from beneficiaries' engagement in all project phases. Moreover, it provides a forward-looking conclusion, including recommendations to further improve self-managed resilience and housing practices.

Keywords: urban resilience, self-managed housing, social housing

\section{INTRODUCTION}

Cities face a multitude of perils, of both anthropogenic and natural origins - from tornadoes to food shortages, from fires to social segregation. They are progressively concentrating wealth and societal functions with increased intensity, amplifying their centrality in the modern world, but also making them even more susceptible to these threats. Within this context, the concept of 'urban resilience' has gained ample prominence, referring to the ability of a city to deal with the problems to which it is exposed, whilst preserving its essential structures and functions.

Resilience frameworks have been developed and employed around the globe, with the use of diverse approaches. These outlooks are built on the different understandings of the hazards cities are exposed to, and associated time and spatial scales involved.

Within these new trends, there is a movement towards empowering people to take action more pro-actively in building theirs, and their cities' resilience. This perspective is the recognition that achieving 'resistance' against all disturbances people are exposed to is an unrealistic hope (Brudermann, Rauter and Yamagata, 2013). Nevertheless, allowing people to not only manage but to also reach a wider spectrum of assets (e.g. jobs, infrastructure and public services) leads to long-term sustainable resilience by adapting and transforming in the face of increasing uncertainty and unpredictability of events.

This article aims to cover urban resilience from the perspective of people's capacity to anticipate, overcome, adapt and transform whilst facing disturbances. More specifically, the growing topic of 'community resilience' is advocated as the one embodying more closely the idea of 'self-managed resilience'. Such approach is portrayed in the case of the self-managed social housing arrangement case of Modalidade Entidades (MCMV-E) within the Minha Casa, Minha Vida Programme (MCMVP) in Brazil, and its potentials to increase resilience in housing - in an individual, community, neighbourhood and at the level of the city.

* Evandro Holz, Urban and International Development Consultant, Berlin, Germany

Email correspondence: evandroholz@gmail.com 


\section{URBAN RESILIENCE APPROACHES}

The field of urban resilience has seen substantial developments, both in theory and practice. For the purposes of this research, the concept is categorised into 'traditional approaches' and 'emerging trends'. The differentiation is made via its underlying theories, and its application ranges in terms of hazard types and spatial and time scales.

\section{Theory}

In very broad terms, resilience refers to the ability of someone or something to recover from a shock or disturbance. As a concept, it has been utilised in a variety of fields, such as economics, engineering, physics, psychology and ecology. Within an urban context, the engineering and ecological models are the ones more widely employed.

The main difference between the engineering and ecological perspectives is regarding equilibrium states. The engineering one, in which the traditional approach is based on, considers only one equilibrium condition, and "refers to the rapidity with which a system returns to its equilibrium after a disturbance" (Wu and Wu, 2013: 213).

The (socio-)ecological vision, on the other hand, understands that a system can have multiple stable states, and evolution is possible as long as the system remains functional, serving as the basis for emerging trends ( $\mathrm{Wu}$ and $\mathrm{Wu}, 2013)$.

The change of states can occur through gradual and continuous (e.g. long-term minor social issues) or abrupt and dramatic (e.g. natural catastrophes) processes.

In addition, slow processes can also incur in sudden events (e.g. long-term social issues resulting into social unrest events) and vice-versa (e.g. flooding event leading to longterm increase in inequality). These are the main characteristics of ecological-systems going through such processes: coping capacities, which are hazard-oriented, and refer to reducing the vulnerability of a system to a certain threat; and adaptive and transformative capacities, which are system-oriented. Adaptation, in this sense, relates to adjusting a system towards minimising impact of future disturbances - in a sense, improving coping capacities; transformation denotes deeper changes, and the reconfiguration of system's dynamics in social, economic and environmental aspects on the longterm, not aiming at addressing a specific issue (Redman, 2014).

The socio-ecological perspective is further described with the concept of Complex Adaptive System (CAS), which implies that the reorganisation of sub-systems due to a shock, ideally prepares the larger system for better adaptation for future events, increasing its resilience (Rodinand and Garris, 2012). In addition, it understands that, whilst the overall city functions are maintained, the structure itself might not be. This can be observed both in terms of components of a larger system (e.g. a disruption in a transmission line leading to an upgrade in the electricity infrastructure), or different spatial and organisational scales (e.g. a community that enhances its capabilities after suffering from flooding events can increase the overall resilience of a metropolitan area).

In summary, CAS embraces change - fighting against it would actually decrease resilience, since its main goal is to adapt, not to prevent.

CAS usually goes through a dynamic and ongoing process of renewal and regeneration which is known as 'adaptive cycle' (Wu and Wu, 2013). Adaptive cycles, in their turn, occur on a broad spectrum of spatial, temporal and organisational scales; the nested hierarchy of adaptive cycles arranged according to their characteristic scales is termed 'panarchy'. Although consisting of a hierarchical structure itself, panarchy is also seen in deliberate contrast with 'hierarchy'. It suggests that slowchanging, large-scale processes influence nested sub-systems, but do not exercise control over them, as dynamic cities are understood to present as well.

Traditional and emerging approaches on urban resilience can be further distinguished through the debate over specific versus general resilience. Specific resilience relates to the particular response of a system towards a known disturbance - the resilience 'of what, to what' (and, more recently, 'for whom'), usually referring to the engineering perspective (e.g. resilience of a neighbourhood to flooding events). In contrast, general resilience is a broader concept, considering the capacity to withstand unforeseen shocks, with no relation to a specific stress or response, related to the ecological view (Wu and $\mathrm{Wu}, 2013)$.

Emulating theory, the scales of application of traditional and emerging urban resilience approaches also entail substantial differences. The debate on specific and general resilience is the one that most influences the spectrum within which urban resilience is assessed. In addition, the incorporation of adaptive and transformative capacities, which include more strongly social and economic factors, is an important determinant. These scales are evaluated in three main instances: hazards, time and spatial scales. 
Cities face both acute and one-off (on a short-term) threats, termed 'shocks', and longer-term perils, or 'stresses'. The traditional approach on urban resilience has a focus on shocks, i.e. mainly events of big magnitude caused by 'external' forces (e.g. floods, storms, hurricanes) and, to some extent, manmade threats (e.g. fires and terrorism), being particularly relevant in natural disaster reduction policies (Beilin and Wilkinson, 2015). New developments have broadened the scope to comprise long-term issues, both from internal and external agents, including more emphatically those of anthropogenic origin. Some examples are problems resulting from ongoing rapid urbanisation, such as segregation and poor housing conditions, migration, tourism, health risks, desertification, declining water quality, etc. In addition, there is a vision towards augmenting a system's capacity towards manifold hazards - embodying the concept of general resilience, rather than focusing on solving issues associated with specific events (Arup and The Rockefeller Foundation, 2014).

Regarding time ranges, two main aspects are considered: the hazard itself, and the associated resilience capabilities/measures involved. As described above, shocks are sudden events and short-time occurrences, characteristic to the traditional approach. Stresses, on the other hand, are long-term issues, or events leading to or resulting from a shock, and have been incorporated by the new vision on urban resilience. Likewise, coping features tend to be shortterm, with closer relation to shocks (e.g. financial resources for reconstruction), while adaptation and transformation (system-oriented) tend to be long-term developments, and more linked to stresses (e.g. improving educational levels). In this case, however, there is no clear distinction - the building and 'use' of such capabilities usually overlap significantly.

Concerning spatial scales, urban resilience entails both cities' sub- and supra-systems, as well as their linkages. Subsystems include territorial subdivisions (e.g. households, neighbourhoods, districts), infrastructure components (e.g. electricity network, solid waste management system, housing, industrial facilities) and populations (e.g. individuals, groups, associations), amongst others. Supra-systems refer to higher level of governments and institutions, international agents, consumers in a different country, etc. In this sense, the traditional approach focuses in the resilience 'of what', i.e. of a particular system, with limited acknowledgement of the linkages between it and other systems; emerging trends, on the other hand, incorporate the understanding that systems are interconnected, horizontally and vertically, and that they influence and are influenced by the others, referring to the concepts of CAS and panarchy.

Although significant evolution of the conceptualisation of urban resilience has been seen, as described above, both traditional and emerging trends still tend to achieve somewhat limited efficacy. Overall, although there is greater consideration of socioeconomic features and linkages between and within urban systems, developments do not properly reflect the pluralistic environment people live in, and that events affect and are affected by people in different ways, bringing uneven level of resilience needs and potentials . A change of paradigm, addressing appropriate scales, and recognising citizens, as individuals and groups, and their assets as systems, and therefore the main drivers of change, is thus deemed necessary. In this study, the concept of 'community resilience' is advocated as the one that better incorporates elements brought by both the traditional and new approaches on urban resilience, but including socioeconomic matters more effusively and being able to work on particularities of individuals and communities.

\section{COMMUNITY RESILIENCE}

Community is a social entity with a greater meaning than the number of people located in a particular territory. It embraces their social and economic relationships, and the sharing of ideas, customs, goals, institutions and services in distinct levels of conformity and conflict (Uriarte Arciniega, 2013). These variables largely determine their strengths and weaknesses, consequently influencing socio-economic impacts of shocks and stresses and coping, adaptive and transformative capacities. Therefore, the concept of community resilience is advocated here not only because it incorporates these aspects more strongly, but also because it embraces the empowerment of citizens and communities to take the lead in "self-managing" resilience.

Community-based organisations and their individuals can offer a particularly valuable set of skills towards building resilience. In general, they leverage their participation with grounded experience and practical knowledge, portraying relevant features such as: organised, informed, experienced constituencies, with a strong commitment to address challenges faced by their communities; field-test practices and solutions; holistic, multi-dimensional approaches to resilient development, due to their already vulnerable conditions, being able to bundle themes and prioritise winwin strategies; and improved responsiveness and accountability of government programmes to their priorities, via ongoing engagement. 
The concepts underlying community resilience can be directly linked to socioecological resilience. From CAS, it takes the vision that change should be embraced, by focusing on adaptive and transformative capacities. From adaptive cycles, it gets the notion of the community as a system within an ongoing process of renewal and regeneration. Drawing on panarchy, it builds on the fact that self-organised actors and processes can affect higher-order system properties. Therefore, the focus on community reflects the acknowledgement that resilience manifests at different levels: individual, household, community, and higher-level systems (e.g. cities, nations and ecosystems) (Frankenberger, Mueller, Spangler and Alexander, 2013).

Several initiatives define characteristics that a resilient community should portray. The outlook provided by Red Cross (IFRC, 2012), for example, defines that a resilient community is the one that...

- ...is knowledgeable and healthy, having the capacities to evaluate and monitor its risks, whilst acquiring new skills.

- ...is organised, and capable of identifying issues, define priorities and act.

- ...is connected, interacting with external stakeholders that can provide support in terms of goods and services, for example.

- ...has infrastructure and services, such as adequate housing, transport, energy, water and sanitation, and associated means to maintain and upgrade these systems.

- ...has economic opportunities, including alternatives for employment, income and financial services, which are flexible, resourceful and reflective to change.

- ...can manage its natural assets, recognising their value whilst protecting, maintaining and improving them.

The societal factors that enable people's accessibility to assets majorly encompass intangible features. The most common denomination describing those is 'social capital', acknowledged as the foundation of collective action, collaboration, and self-organisation.

Social capital can be divided into three types (Frankenberger, Mueller, Spangler and Alexander, 2013):
- Bonding social capital: defined as the links between community members, including principles such as trust, cooperation, and solidarity.

- Bridging social capital: refers to the connections of one community/group to other communities/groups. It can facilitate access to a broader range of external assets and it can cross physical and cultural barriers.

- $\quad$ Linking social capital: depicts more 'vertical' networks between individuals and groups interacting with institutionalised and formal entities in the society.

Resilience, as a discursive formation, can provide a powerful tool for establishing power relations with these institutions.

Assets and resources alone, however, are not sufficient to characterise community resilience - it is their quality that determines it (IFRC, 2012). Additionally, the capacity of persons to cope with threats and learn from them, whilst adjusting to future crises, is not only based on their own willingness. The case study described next assesses to which extent such characteristics can be present in (self-managed) social housing programmes.

\section{RESILIENCE IN SOCIAL HOUSING}

Massive social housing programmes such as the MCMVP tend to represent both a shock and a stress to the community itself, its surroundings, and the city as a whole.

They have the potential to destroy the continuity and resilience of cities if not adequately planned and implemented. They characterise a rapid and possibly brutal transformation of urban fabric, due to the sudden increase in population in an area, and consequent demand for public services and infrastructure. In addition, they derive from and can result in long-term stresses, since such settlements accommodate populations facing socio-economic struggles, and due to potential issues with the settlements (e.g. limited connectivity to the city), can lead to similar or new stresses (e.g. loss of job due to increased commuting distance).

Self-managed arrangements as the one provided by MCMV$\mathrm{E}$ have the potential to minimise the issues described above whilst improving their beneficiaries' resilience in social, economic and environmental terms. This potential mainly derives from the collaborative nature of such provisions, 
which allows beneficiaries, through participation processes, to have a say on several aspects of the project, such as location, design, settlement layout, engagement with municipality and surrounding communities, amongst others.

In the case of MCMV-E, the structure revolves around an entity (entidade) which is responsible for the management and development of the housing project. Works are supported by two committees - one accountable for the financial management, the other one for the construction oversight. Both of them have their members decided on an assembly and should include at least one beneficiary of the programme (Caixa, n.d, 2016). In addition, technical assistance groups tend to play a big role as well, providing support in going through bureaucratic processes, assisting in technical aspects of the project, offering capacity-building activities, etc. Government backing is provided by municipalities (although limited due to usual shortage of resources) and national level, particularly regarding financing and subsidies, and technical compliance, all conducted by the national bank Caixa.

Social works are another big part of the programme, involving capacity-building activities throughout the project lifecycle, as described below (Caixa, n.d, 2016):

- Pre-construction: education on basic concepts of community organisation alternatives and possibilities for representation of the beneficiaries, management of the housing estate, budget administration and cost saving strategies.

- During construction: as a minimum, education on community organisation, environment, heritage, planning and management of household budget, and job generation and income.

- Post-occupancy: consolidation of the processes implemented during previous phases; completion of the activities conducted by monitoring committees; empowerment of the implemented organisations; evaluation of the conducted processes and associated products; information regarding the beneficiary satisfaction with the housing unit and local infrastructure, urban insertion, and social development of the community.

The opportunity to actively participate as the main agents, as decision-makers of the project and to engage in capacitybuilding are the main drivers of increasing bonding capacities between the beneficiaries (NEPAC-Unicamp, 2015; Lago et al., 2012). Such activities greatly increase their social networking and can be directly linked to adaptive and transformative capacities, since they empower people to proactively take decisions over matters of their interest, capacitate them to use existing assets with more proficiency, and pursue new assets if needed.

In terms of bridging social capital, the networking of a MCMV-E community is seen as particularly relevant with four agents: surrounding communities, similar housing initiatives, construction companies and technical assistance groups. The widening of the network of the community is also important in building adaptive and transformative capacities, by allowing people to capture assets from a wider spectrum of possibilities. As examples, good relationship with neighbours allow the use of additional public facilities and increased bargain power when demanding better public services, and better-planned settlements can be developed in cooperation with contractors and technical advisors (Lago et al., 2012; Jesus, 2015).

Furthermore, the relationship of the community and the entity with formal institutions, in particular government bodies, is vital for the building of transformative capacities. The MCMVP, in its core, is drawn on a decentralisation process, providing autonomy to local governments in the institutional and legal realms to set up initiatives in housing and other urban related matters (UN-Habitat, 2013). In theory, the greater closeness of the local government to the entity and to project brings the possibility of a more tailored relationship, enhancing the openness for the negotiation of demands, for example. In addition, a good engagement with the local government, including its support in negotiating land, can be of significant aid by, for example, establishing credibility for the entity towards the land owners, since selfmanaged housing initiatives remain relatively unknown (Lago et al., 2012). In reality, however, the low technical and political capacity of most municipalities has not led to substantial levels of support in this regard (UN-Habitat, 2013).

In economic terms, although MCMV-E faces similar issues in accessing affordable and decently located land, it has great potential to increase resilience of the beneficiaries. In the beneficiaries' selection phase, for example, there is a priority for people that work close to the new settlement, or currently live in unaffordable houses (Caixa, n.d, 2016). Also, there are possibilities (although limited due to availability of land) of beneficiaries selecting the location, taking into consideration the proximity to jobs, developing scattered units, or redeveloping existing housing states 
(sometimes donated by the government) (Majcen, 2015). During the construction, capacity-building programmes allow residents to apply the newly acquired knowledge in their professional lives. Post completion, in addition to taking advantage of the actions from previous phases, residents can engage in economic activities within the settlement or in public services (e.g. new schools or health facilities) made available nearby the settlement (Observatório das Metrópoles, 2011). Moreover, the programme is highly subsidised, and instalments can be covered to up to $90 \%$ by a fund designated by the federal government. Furthermore, there is a zero interest rate over payments and a grace period of thirty six months after the signature of the contract, amongst other benefits which greatly reduce the burden over beneficiaries.

Compared to socio-economic factors, environmental aspects appear to be the lowest priority at the MCMVP, at least directly. Understandably, socio-economic issues tend to be the focus since these characterise more urgent matters, and budget is naturally severely limited. Nevertheless, the better infrastructure encountered in MCMV-E settlements does present lower environmental impacts and contribute to health improvements, for example through improved waste disposal and potable water access. Another major role played by MCMV-E is the prioritisation of families living in risk areas, or that have been displaced, most notably due to environmental issues.

Overall, as depicted above, if properly implemented, MCMV$\mathrm{E}$ (and similar selfmanaged arrangements) can provide an ample range of opportunities for increasing the resilience of its beneficiaries, their communities and their cities. In a scenario of crisis and change - entailing socio-economic issues, lack of adequate housing and moving to a new settlement - it provides people with an opportunity to utilise such context to improve their capabilities and broaden their access to tangible and intangible assets. The main driver for such potentials lies in the collaborative nature of the programme: it allows not only physical structures but also management and capacity-building activities to be tailored according to the particularities of the community and its individuals. Naturally, implementation of self-managed initiatives presents several challenges; the main ones are already well-known: achieving good levels of inclusive participation; juggling with limited resources among several priorities; and shortage of technical knowledge and resources in the entity and associated institutions, particularly in local governments.

\section{CONCLUSIONS AND WAY FORWARD}

The evolution of the conceptualisation and practice of urban resilience reveals remarkable insights. Its concept has been broadened from an emphasis on endurance of functions, through a focus on adaptability of systems, towards transformative capabilities in the face of uncertainty and unpredictability of events (Keck and Sakdapolrak, 2013). Interestingly enough, this evolution has not ruled out the need for the employment of more traditional approaches and it is highly unlikely it will within the foreseeable future. The combination of both traditional and emerging practices, and/or the utilisation of a point in between these two, depending on local circumstances, appear to be an enduring rule for implementation of such initiatives.

The improvement of resilience in communities is in the struggle for stability, recovery, adaptation and transformation. In this sense, resilience refers more to communities' inherent capacities than to the external resources they can obtain. In addition, it is often during crises that the most positive qualities thrive, including those that had not been previously acknowledged, in particular in terms of individual strength and collaborative work towards a common good (Uriarte Arciniega, 2013).

First and foremost, resilience is about governance. At the same time, we expect governments and organisations to do things for people, but we mistrust them to deliver (Multinational Resilience Policy Group, 2015). Resilience is already built on a dailybasis - when people engage in improving environmental conditions in their neighbourhood, participate in responsible consumption or human rights initiatives, and so on (Uriarte Arciniega, 2013). In this sense, governments have to be institutions that support communities to perform things for themselves, enabling them to be in charge and strengthening what already works well.

Making use of the attention that has been given to resilience whilst combining its concept with other developments (as social housing) seems to be the most viable way to increase the feasibility of such practices. This can be envisioned as a two-way process: in the case of self-managed social housing, for example, 'increasing resilience' can serve as an argument to encourage the utilisation of self-managed housing; likewise, housing itself, usually being more easily politically accepted, can indirectly assist in boosting resilience practices. 
In general, urban resilience does not substantially differ from many city-related practices. A constant struggle for political and financial support exists, reinforcing the need for combination of resilience with other developments to strengthen arguments towards achieving overarching objectives. Above all, there should be great consideration over the diversity of people and the distinct environments they live in, and the fact that circumstances are always bound to change. Allowing for continuous progress in face of shocks and stresses, whilst taking into account people, community and city limitations and potentials, appears to be a most feasible way forward.

\section{REFERENCES}

Arup and The Rockefeller Foundation, 2014, City Resilience Framework. City Resilience Index. [online] p.21. Viewed 14 July 2015 from:<https:/www.rockefellerfoundation.org/report/city-resilience-framework/>

Beilin, R. and Wilkinson, C., 2015, “Introduction: Governing for urban resilience”, Urban Studies, 52(7), $1205-1217$.

Brudermann, T., Rauter, R. and Yamagata, Y., 2013, "Behavioral Aspects of Urban Resilience, Innovation and Supply Chain Management, 7(3), 83-91.

Caixa, n.d. Programa Minha Casa Minha Vida Entidades - Recursos FDS. Viewed 1 May 2016 from:

$<$ http://www.caixa.gov.br/Downloads/habitacao-minha-casa-minhavida/MANUAL_MCMV_ENTIDADES.pdf>

Frankenberger, T., Mueller, M., Spangler, T. and Alexander, S., 2013, Community Resilience: Conceptual Framework and Measurement. Feed the Future Learning Agenda, US AID, p.49, Viewed 6 October 2015 from:

$<$ https://agrilinks.org/library/communityresilience- conceptual-framework-and-measurement-feed-future-learning-agenda $>$

IFRC, 2012, Understanding Community Resilience and Program Factors that Strengthen them: A Comprehensive Study of Red Cross Red Crescent Societies Tsunami Operation. Geneva, Switzerland, p.19, Viewed 9 October 2015 from: $<\mathrm{http}: / /$ www.alnap.org/resource/7899>

Jesus, P.M. de, 2015, O Programa Minha Casa Minha Vida Entidades em São Paulo e Região Metropolitana. [text], Viewed 6 October 2015 from: Universidade de São Paulo. Available at: <http://www.teses.usp.br/teses/disponiveis/8/8136/tde$16062015-141838 />$

Keck, M. and Sakdapolrak, P., 2013. "What is Social Resilience”, Erdkunde, 67(1), 5-19.

Lago, L., Mineiro, E., Rodrigues, E., Drago, F., Mello, I., Naime, J., Wartchow, J. and Ferreira, R., 2012. Autogestão Habitacional no Brasil: Utopias e Contradições. Rio de Janeiro: Letra Capital: Observatório das Metrópoles.

Majcen, K., 2015. After 7 Years of Struggle, Rio's Latest Cooperative Public Housing is Nearly Ready. RioOnWatch, Viewed 6 October 2015 from: <http://www.rioonwatch.org/?p=23232>

Multinational Resilience Policy Group, 2015, "Strategies for Supporting Community Resilience: Multinational Experiences". CRISMART.

NEPAC-Unicamp, 2015. Avaliação do Programa Minha Casa, Minha Vida-Entidades. O desafio da participação dos beneficiários. [online] Campinas, SP, Brazil, Viewed 6 October 2015, from: <http://www.nepac.ifch.unicamp.br/pt$\mathrm{br} / \mathrm{pa} /$ avalia $\% \mathrm{C} 3 \% \mathrm{~A} 7 \% \mathrm{C} 3 \% \mathrm{~A} 3$ odo-programa-minha-casa-minha-vida- $\% \mathrm{E} 2 \% 80 \% 93$-entidades-o-desafio-daparticipa $\%$ $\mathrm{C} 3 \% \mathrm{~A} 7 \% \mathrm{C} 3 \% \mathrm{~A} 3 \mathrm{o}-\mathrm{dos}>$

Observatório das Metrópoles, 2011. Minha Casa, Minha Vida: experiências de autogestão coletiva. [online] Observatório das Metrópoles. Viewed 6 October 2015 from:

$<$ http://observatoriodasmetropoles.net/index.php?option $=$ com_content\&view $=$ article \&id $=1713 \&$ catid $=45 \& I t e m i d=88 \& 1$ ang $=\mathrm{pt}>$

Redman, C.L., 2014. Should Sustainability and Resilience Be Combined or Remain Distinct Pursuits? Ecology and Society, [online] 19(2). Viewed 5 January 2016 from: <http://www.ecologyandsociety.org/vol19/iss2/art37/>

Rodinand, J. and Garris, R., 2012, "Reconsidering Resilience for the 21st Century", in: Frontiers in Development. USAID, $110-120$. 
The World Bank, 2015, “Community-Led Partnerships for Resilience”, Washington, DC: The World Bank: 72.

UN-Habitat, 2013. Scaling-Up Affordable Housing Supply in Brazil: The 'My House My Life' Programme. [online] 120. Viewed 15 August 2015 from: <http://unhabitat.org/scaling-upaffordable- housing-supply-in-brazil/>

Uriarte Arciniega, J.D.D., 2013, “La Perspectiva Comunitaria de la Resiliencia”, Psicología Política, (47): 7-18.

Wu, J. and Wu, T., 2013. Ecological Resilience as a Foundation for Urban Design and Sustainability. In: S.T.A. Pickett, M.L. Cadenasso and B. McGrath, eds., Resilience in Ecology and Urban Design, Future City. [online] Springer Netherlands, 211-229. Viewed 21 November 2015 from: <http://link.springer.com/chapter/10.1007/978-94-007-5341-9_10> 